\title{
How Specialists Become Primary Care Physicians in Japan
}

\section{Takuma Kato, Naoki Ikegami}

Keio University, Tokyo, Japan

Email: kato-takuma@umin.net

How to cite this paper: Kato, T. and Ikegami, N. (2019) How Specialists Become Primary Care Physicians in Japan. Health, 11, 322-331.

https://doi.org/10.4236/health.2019.113028

Received: February 3, 2019

Accepted: March 10, 2019

Published: March 13, 2019

Copyright $\odot 2019$ by author(s) and Scientific Research Publishing Inc. This work is licensed under the Creative Commons Attribution International License (CC BY 4.0).

http://creativecommons.org/licenses/by/4.0/

\begin{abstract}
Background: Most countries have a shortage of Primary Care (PC) physicians. Japan has mitigated this problem by specialists making a mid-career change to PC when they go into private practice. This study examines the circumstances under which specialists shift to PC. Methods: Since the division between specialists and PC physicians is blurred in Japan, we focus on Physicians Providing Home Visits (PPHV). The list of PPHV was obtained from the local medical associations in two neighboring medical planning areas in Japan. The methods used were a questionnaire and in-depth interviews. Results: Of the 46 listed as PPHV, 38 responded to the questionnaires. Physicians mainly acquired their knowledge and skills in primary care from post-graduate clinical training and on the job training after becoming PPHV. The specialists who had moved to PC were equally knowledgeable regarding PC as those had taken the PC accreditation exam. The in-depth interviews revealed that the higher income earned in clinics and being able to retain their identity as a specialist were also important factors. Conclusions: The factors that contributed to physicians making a mid-career change from specialists to PC were their experiences after being certified, the higher income in clinics and the ability to retain their professional identity as specialists. These enabling factors might also be applicable for increasing the ratio of PC physicians at the global level although further studies are required.
\end{abstract}

\section{Keywords}

Mid-Career Changes, Primary Care, Specialists, Professional Identity

\section{Background}

\subsection{Health Service Delivery and Shortfall of Physicians}

Health workforce is a critical component for achieving Universal Health Cover- 
age (UHC), which is advocated in SDGs 2030 agenda [1]. The national strategy on health workforce should consider the shortage, distribution, education, performance and migration of health workforce. The inappropriate distribution and shortage of physicians have been a common challenge in almost all countries [2].

\subsection{Shortage of Primary Care Physicians in the World}

Although the countries that are more focused on primary care (PC) have been shown to achieve better health at lower cost [3] [4], the number of primary care physicians has not increased, while specialists have steadily increased [5] [6]. Almost all physicians want to become specialists in low- and middle-income countries, exacerbating the mal-distribution [7]. Once they have become specialists, they are likely to remain in urban hospitals. Interventions to mitigate the mal-distribution have generally found to be unsuccessful [8].

\subsection{Primary Care Physicians in Japan and Mid-Career Changes}

Nearly all the physicians providing primary care have practiced as specialists in hospitals before going into private practice in office clinics at middle age because, firstly, the formal system of educating and training physicians in primary care has been slow to develop. Thus, there are very few physicians who have been formally trained in primary care. Secondly, almost all the clinics are solo-practices so that it would be difficult for the physicians to focus only on their specialty for which they have been trained. Thirdly, almost all hospitals maintain large outpatient departments so that patients needing specialist care tend to gravitate towards hospitals [9] [10]. For these reasons, most physicians in clinics tend to focus on primary care. However, these physicians in clinics continue to identify themselves as specialists, which is why the boundary between specialists and primary care physicians is not clear in Japan [11].

The Ministry of Health, Labour and Welfare (MHLW) has made several attempts to more systematically educate and train physicians in primary care. First, the departments of primary care or "comprehensive practice", which covers general medicine, family medicine, and general hospitalists, have been established in a majority of medical schools [12]. However, the number of primary care physicians they have trained remains very few. Second, a two-year program introduced in 2004 required that all newly licensed physicians must complete a two-year course rotating among the basic departments such as internal medicine and surgery so that they would be able to deliver basic services including primary care [13]. However, the extent to which those completing this program have acquired the skills needed in primary care has not been evaluated. Third, the Japan Primary Care Association was established in 2010 through the merger of three societies respectively focused on PC, Family Physicians and General Physicians [14]. Since their merger, those who have met the prescribed conditions have been certified as a "general physician specialist". However, the number certified is about 7000 in 2016, composing only $2.2 \%$ of all physicians [12]. Lastly, the process of becoming a specialist was formalized in 2018. However, this has 
meant that those who wish to be certified as a "general physician specialist" must enroll in this program because it has been designated as the 19th basic specialty within the Japanese Medical Specialty Board (JMSB) in 2017 [15]. Given the desire of recently graduated physicians to become organ specialists and the scarcity of programs in PC, establishing PC as a basic specialty may actually lead to a decrease in the number of physicians who deliver PC.

\section{Objectives}

Our objectives are the following: 1) Examine how physicians became focused on PC. 2) Examine whether these physicians have adequate knowledge of PC and the process of acquiring the knowledge and skills. 3) Elucidate the reasons for making their career change from specialists to PC physicians. Since it is difficult to identify PC physicians in Japan, this study has focused on the physicians listed in the "Physicians Providing Home Visits (PPHV)" by the local medical association. While other physicians would also be providing primary care, since we had no other means of identifying those who are focused more on PC than on specialist care, we conducted our study on these physicians.

\section{Methods}

\subsection{Study Design}

We used a combination of quantitative research using a questionnaire and qualitative research by in-depth interviews. Both surveys were conducted in two adjacent medical care planning areas in Nagano Prefecture (Japan is divided into 344 planning areas). The two areas covered $2477 \mathrm{~km}^{2}$, with a total population of 419,240 [16], of which $26.4 \%$ were 65 and over, which is somewhat higher than the national average of $25.9 \%$. In all, 778 physicians practiced in the two areas (2014) [17].

\subsection{Sampling}

In this study, the subjects were all the physicians listed in PPHV in the two medical planning areas. Almost all of physicians who are focused on providing home visits are likely to be listed because they would be able to network and share information on home visits. If there were two or more physicians in each clinic, we sent the questionnaire to both. However, we limited the subjects to those who were working full time in the clinics.

\subsection{Preliminary Study}

A preliminary interview study was conducted on a convenience sample of ten from the PPHV list in order to design the questionnaire and in-depth interview. Draft questions were derived from a review of the literature on primary care physicians in Japan and our experience [18]. The questions asked for their age, sex, years of experience, time spent on home visits, their knowledge on primary care, methods they had used to acquire skills and knowledge, and the reasons for 
being listed in the PPHV.

\subsection{Quantitative Research with Questionnaire}

Based on the results of the preliminary interview study, we revised the questions about their experience and knowledge. To more objectively compare their knowledge level with that of the physicians who have been certified in PC, we asked a board member of the Japan Primary Care Association (JPCA) to provide us with a modified version of the questions they would use in their certification examination. The questionnaire was posted to all of the subjects listed in the PPHV.

\subsection{Analysis of Questionnaire}

T-test was applied to analyze the knowledge scores on PC in comparison with the standard of $70 \%$, which is used as the cut-off point in JPCA A significance level equal to or less than 0.050 was considered significant. The SPSS 24 (SPSS Inc., Chicago, IL, USA) software was used to analyze the data from questionnaires.

\subsection{In-Depth Interview}

To better understand the responses made in the questionnaire and prove areas that the questionnaire cannot elucidate, in-depth interviews in explanatory sequential design were conducted on 3 subjects. These subjects were selected from the responders who had voluntarily written their names in the questionnaire. The interview focused on the following semi-structured questions in framework. 1) Method of acquiring skills and knowledge on primary care. 2) Reasons why they had changed their move to a clinic. 3) The extent to which they were influenced by their income prospects in making their career change. These questions were chosen because, based on the preliminary study, in particular monetary questions, would be difficult to respond in the questionnaire.

\subsection{Analysis of Interview}

The responses of in-depth interview were analyzed based on grounded theory with opened coding. The findings were selected and analyzed in line with the objectives of this study based on the researcher's interpretation and deduction, and interpreted together with the quantitative data analysis through triangulation.

\subsection{Ethical Issue}

This study was approved by the ethics committee of the Saku Central Hospital, Japan. In order to meet some issues in ethical aspect, we collected the questionnaire with voluntary signature. The original records remain confidential and have never been disclosed.

\section{Results}

Thirty eight physicians out of the 46 listed responded to the questionnaires during the study period making the response rate $82.4 \%$. However, we decided to 
exclude the three who had replied that they had been dispatched temporally from hospitals to the clinics on a rotational basis. Thus, the number of effective responses was 35. Table 1 shows the general characteristics of these 35 subjects: about $90 \%$ of the subjects have some certification as a specialist. More than half of physicians have kept their specialist certification after moving to their clinics.

Table 2 shows that the main methods for acquiring knowledge and skills needed in primary care were post-graduate clinical training (65.7\%) and on-the-job training (62.9\%). The reasons for shifting from specialists to primary care physicians were mainly "Contributing to the community" (45.7\%), "Avoid relocation" (25.7\%) and "Less physical burden" (22.9\%).

The score analysis showed the subjects' basic PC knowledge did not significantly differ from the standard of the accreditation by JPAC, 70\% (Average $67.1 \%$, Margin to $70 \%[95 \% \mathrm{CI}]-2.86[-11.91-6.19])$. Table 3 clarified that "learning while working as a specialist" significantly contributed to the subjects' learning and maintenance of PC their knowledge as a result of multivariate logistic regression.

Table 1. Socio-demographic characteristics of the physicians providing home visit in two areas.

\begin{tabular}{|c|c|c|}
\hline Variables & & \\
\hline Sex & Male & $33(94.3 \%)$ \\
\hline Age & Median $[1 / 4,3 / 4]$ & $\begin{array}{c}50-54 \\
{[45-49,55-59]}\end{array}$ \\
\hline Number of years providing home visits & Mean (SD) & $13.57(\mathrm{SD}=8.3)$ \\
\hline Hours devoted to home visit (hrs/wk) & Mean (SD) & $4.7(\mathrm{SD}=3.0)$ \\
\hline & University Hospital & 5.6 yrs $[0-15]$ \\
\hline Average years working in each site: & Community Hospital & 8.1 yrs [0 - 27] \\
\hline & Clinics & 14.2 yrs $[1-31]$ \\
\hline \multirow{9}{*}{ Specialists' certification } & All certification & $31(88.6 \%)$ \\
\hline & Area & \\
\hline & Internal medicine specialties & $20(57.1 \%)$ \\
\hline & Surgical specialties & $9(25.1 \%)$ \\
\hline & Others & $2(5.8 \%)$ \\
\hline & No certification & $4(11.4 \%)$ \\
\hline & Multiple/Single & \\
\hline & Multiple & $15(42.9 \%)$ \\
\hline & Single & $16(45.7 \%)$ \\
\hline \multirow{3}{*}{$\begin{array}{c}\text { Medical Specialty(ies) proclaimed in } \\
\text { their clinics }\end{array}$} & Multiple & $22(62.9 \%)$ \\
\hline & Single & $13(37.1 \%)$ \\
\hline & Including any without certifications & $26(74.3 \%)$ \\
\hline
\end{tabular}

*Multiple answers. 
Table 2. Methods to acquire knowledge and skills and reasons for deciding to move to a clinic.

\begin{tabular}{|c|c|}
\hline \multicolumn{2}{|c|}{ Methods to acquire primary care knowledge and skills $[\mathrm{N},(\%)]^{*}$} \\
\hline Post-graduate clinical training & $23(65.7 \%)$ \\
\hline Learning while working as a specialist & $10(28.6 \%)$ \\
\hline Specific lectures lasting more than one month & $1(2.9 \%)$ \\
\hline Short-course lectures & $2(5.7 \%)$ \\
\hline Guidance from physicians engaged in home visits & $7(20.0 \%)$ \\
\hline On-the-job training & $22(62.9 \%)$ \\
\hline Others & $1(2.9 \%)$ \\
\hline \multicolumn{2}{|c|}{ Reasons for deciding to move to a clinic $[\mathrm{N},(\%)]^{*}$} \\
\hline Contributing to the community & $16(45.7 \%)$ \\
\hline Change of interests & $2(5.7 \%)$ \\
\hline Higher income & $1(2.9 \%)$ \\
\hline Less time constraints & $5(14.3 \%)$ \\
\hline Less physical burden & $8(22.9 \%)$ \\
\hline Avoid relocation & $9(25.7 \%)$ \\
\hline Others & $14(40.0 \%)$ \\
\hline
\end{tabular}

${ }^{\star}$ Multiple answers.

Table 3. Analysis of factors influencing to PC knowledge scores.

\begin{tabular}{lccc}
\hline Factor & B & S.E. & P-value \\
\hline Age & -0.51 & 0.41 & 0.21 \\
\hline Experience years & 0.01 & 0.07 & 0.87 \\
\hline $\begin{array}{l}\text { Specialists classification } \\
\quad \text { Internal medicine specialties }\end{array}$ & -4.40 & 2.93 & 0.20 \\
$\quad \begin{array}{l}\text { Surgical specialties } \\
\text { Others }\end{array}$ & -1.60 & 2.13 & 0.45 \\
$\quad-4.52$ & 2.81 & 0.11 \\
\hline $\begin{array}{l}\text { Methods to acquire primary care knowledge and skills } \\
\quad\end{array}$ & -2.77 & 1.78 & 0.12 \\
$\quad \begin{array}{l}\text { Post-graduate clinical training } \\
\text { Learning while working as a specialist }\end{array}$ & -3.62 & 1.48 & 0.02 \\
$\quad \begin{array}{l}\text { Guidance from physicians engaged in } \\
\text { home visits } \\
\quad \text { On the job training }\end{array}$ & 1.44 & 1.67 & 0.39 \\
\end{tabular}

Table 4 shows the summary of the in-depth interviews, mainly to the planned key questions based on grounded theory approach.

\section{Discussion}

The results first confirmed our assumption that the greater majority of PC 
Table 4. Methods for acquiring the skills and knowledge on primary care, and the reasons why they made a career change to clinics.

\begin{tabular}{|c|c|}
\hline Concepts/Codes & Interviewee's original comments \\
\hline \multicolumn{2}{|c|}{ Key question A) Detailed methods of acquiring skills and knowledge on primary care } \\
\hline $\begin{array}{l}\text { Rotation training in internal } \\
\text { medicine }\end{array}$ & $\begin{array}{l}\text { "At the beginning of the training in internal medicine, I rotated } \\
\text { among several sub-specialties, including cardiology, pneumology } \\
\text { and so on within internal medicine over several years". }\end{array}$ \\
\hline Night shift in emergency room & $\begin{array}{l}\text { "I treated all patients while on night shifts in the emergency } \\
\text { room, and could consult with specialists when needed". }\end{array}$ \\
\hline $\begin{array}{l}\text { Conditions of billing in the fee } \\
\text { schedule }\end{array}$ & $\begin{array}{l}\text { "I could understand the primary care services I should provide by } \\
\text { looking at the items and conditions of billing in the fee schedule". }\end{array}$ \\
\hline \multicolumn{2}{|c|}{ Key question B) Concrete reasons for making the move to the clinic } \\
\hline $\begin{array}{l}\text { Flexibility of the specialist's } \\
\text { recertification }\end{array}$ & $\begin{array}{l}\text { "We are able to retain our certification as specialists. This could } \\
\text { be the key factor for maintaining my motivation to improve my } \\
\text { skills in clinics". }\end{array}$ \\
\hline To remain in the same area & $\begin{array}{l}\text { "I didn't want to move out of this area because I was attached to } \\
\text { it and for the sake of my children's education". }\end{array}$ \\
\hline \multicolumn{2}{|c|}{ Key question C) Influence of higher income of PC physicians } \\
\hline $\begin{array}{l}\text { Able to improve income, not } \\
\text { direct reason, push greatly }\end{array}$ & $\begin{array}{l}\text { "I was confident that I would have a higher income, This pushed } \\
\text { me greatly". }\end{array}$ \\
\hline Factor for making the change & $\begin{array}{l}\text { "Higher income if I moved to the clinic might be a factor which } \\
\text { pushed me to move from the university hospital". }\end{array}$ \\
\hline
\end{tabular}

physicians had been trained as a specialist before they went into private practice in clinics. Second, although higher income was not cited as the reason for making a mid-career change in the questionnaire, both the preliminary interview and the in-depth interviews revealed that it was an important factor together with less physical burden and time constraints. This is probably due to the Japanese cultural norm that had made it difficult to explicitly cite monetary reasons. Third, despite the lack of formal training in PC, their knowledge level was on the same level as those who had been accredited by the Japan Primary Care Association. Whether this system is sustainable in Japan, and whether it is applicable to other countries will be discussed.

First, the tightening of certification and recertification standards by the JMSB in 2018 may lead to fewer physicians going into private practice and focusing on primary care, because it would become harder for them to be recertified as a specialist. The latter would be a blow to their professional identity as a specialist. The in-depth interview showed that being able to retain their specialists' certification was a key component for maintaining their identity as specialists.

Second, up to now, the income of physicians in clinics was about 1.7 times that of the physicians working in hospitals in 2010 because their interests have been well presented by the Japan Medical Association (JMA) [19]. However, as specialist associations gain more power; their services would be favored more at the expense of PC services. Parenthetically, specialists have tended to be weakly 
organized because of the rivalry among the university clinical departments.

Given these conditions unique to Japan, there are major caveats in generalizing our results to other countries. However, counter-balancing the wishes of the newly licensed physicians to become specialists tend to be universally difficult. Moreover, their higher professional prestige tends to be also reflected in their income. Enabling PC physicians to earn higher incomes and reducing their work burden, while continuing to recognize their status as specialists, could be the way forward. In particular, although the standards for certification and recertification should be made more rigorous to ensure quality, there should also be opportunities for specialists to make mid-career changes to PC.

Finally, there are major limitations in our study. First, the subjects were extracted from only 2 rural medical planning areas. The number of medical schools, population density, demographic composition and the like in these areas might have affected our results. However, it has been extremely difficult to conduct studies with reasonable response rates on PC physicians. In the studies made by the Japan Medical Association, which has been highly supported by private practitioners, the response rate has only been about 50\% [20], We were able to obtain an a response rate of over $80 \%$ because one of the authors had worked in the key hospital in the two areas and was therefore able to establish formal and informal relationship with the local physicians. Second, questions on their knowledge of PC were limited in number and based only on the written part of the JPCA certification examination, and did not include Objective Structured Clinical Examination (OSCE) nor questions on their ability to coordinate care [14]. Finally, we did not attempt to evaluate how successfully the PC physicians were able to deliver a comprehensive range of PC services such as coordinating care with hospitals.

\section{Conclusion}

Our study showed that specialists in hospitals had made mid-career shifts to become PC physicians in clinics typically after more than 10 years practicing in hospitals. The reasons for doing so were as follows: their experience in practicing PC during their post-graduate training and night duties, and the flexible process of recertification as specialists that allowed them to gradually shift towards PC, yet retain their professional identity as specialists. In addition, in-depth interviews showed that higher income as private practitioners in clinics was also a promoting but not a decisive factor. Their knowledge of PC appeared to be on the same level as those who were certified as "general physician specialists" by the JPCA and reinforced by learning while working as a specialists. However, the tightening of the standards for the certification and recertification of specialists, which are necessary for improving the quality of specialists, may lead to a sharp decrease in those who would make this shift. How PC has developed in Japan may provide both positive and negative lessons to countries that are planning to increase the number of physicians at the PC level. For the application or sharing 
of the positive lessons, the further studies must be made in Japan and other countries.

\section{Conflicts of Interest}

The authors declare no conflicts of interest regarding the publication of this paper.

\section{References}

[1] Sustainable Development Goals 17 Goals to Transform Our World. http://www.un.org/sustainabledevelopment/health/

[2] WHO (2011) Skilled Health Professionals Density (per 10000 Population). http://apps.who.int/gho/indicatorregistry/App_Main/view_indicator.aspx?iid=4667

[3] Caley, M. (2013) Remember Barbara Starfield : Primary Care Is the Health System's Bedrock. BMJ, 347, 2-3. https://doi.org/10.1136/bmj.f4627

[4] Starfield, B. and Shi, L. (2007) Commentary: Primary Care and Health Outcomes: A Health Services Research Challenge. 2252-2256.

[5] Arc, M., Ivo, L.R. and Indig, A.A.K. (1996) A Report Card on the Physicians Work Force in the United States.

[6] Lenzer, J. (2015) Less than a Fifth of US Medical Students Choose Primary Care. British Medical Journal, 342, 998-999.

[7] Dussault, G. and Franceschini, M.C. (2005) Human Resources for Health Not Enough There, Too Many Here: Understanding Geographical Imbalances in the Distribution of the Health Workforce.

[8] Grobler, L., Marais, B.J. and Mabunda, S. (2015) Interventions for Increasing the Proportion of Health Professionals Practicing in Rural and Other Underserved Areas. Cochrane Database of Systematic Reviews. https://doi.org/10.1002/14651858.CD005314.pub3

[9] Ministry of Health, Labour and Welfare in Japan (2016) The Survey of Physicians, Pharmacists and Dentists 2016.

[10] Ministry of Health, Labour and Welfare in Japan (2016) The survey of Health Institution 2016

[11] OECD (2014) OECD Reviews of Health Care Quality: Japan Raising Standards Assessment and Recommendations. Review of Health Care Quality.

[12] Tomioka, S. (2017) Comparison of 5 Qualifications of Primary Care and the Education of Primary Care. Social Insurance Ten-Day Reports, Tokyo, 10.

[13] Ministry of Health, Labour and Welfare in Japan (2004) Physician's Initial Clinical Training. http://www.mhlw.go.jp/topics/bukyoku/isei/rinsyo/keii/

[14] Japan Primary Care Association (2010) History of Japan Primary Care Association. http://www.primary-care.or.jp/jpca_eng/index.html

[15] Japanese Medical Specialty Board. http://www.japan-senmon-i.jp/aboutus/history.html

[16] Statistics Japan (2015) National Census.

[17] Ministry of Health, Labour and Welfare (2014) Survey on Medical Doctor, Dentists and Pharmacists.

[18] Kato, K., Yamauchi, K., Miyaji, M., Fujiwara, N., Katsuyama, K., Amano, H., Kobayashi, S., Naito, M., Maki, Y., Kawahara, H., Maseki, M. and Senoo, Y. (2012) 
Factors Relating to Doctors' Desire to Change Hospitals in Japan. International Journal of Health Care Quality Assurance, 25, 19-40.

[19] Ministry of Health, Labour and Welfare (2017) Difference on Income between Physicians in Clinics and in Hospitals.

http://www.mhlw.go.jp/bunya/iryouhoken/iryouhoken12/iryouhoushu.html

[20] Japan Medical Association (2009) The Questionnaires of Current Motivation for Opening and Situation of Physicians in Clinics. Japan Medical Association, Tokyo. 